\title{
The benefit of seat belt legislation in the United Kingdom
}

\author{
MARK McCARTHY \\ From the Department of Community Medicine, University College, London.
}

ABSTRACT Legislation for compulsory wearing of seat belts by car drivers and front seat passengers has been acclaimed as a major public health advance. Reports from other countries, and two recent evaluative studies in the United Kingdom, have suggested that legislation reduces both deaths and injuries. To assess the effect of the UK law 5 years after its implementation, trends in routine data for 1976-1987 have been reviewed. There were two sources of data: mortality statistics, published by the Office of Population Censuses and Surveys in the quarterly Monitor DH4, and road accident statistics, recorded by the police and published by the Department of Transport. There is a downward trend in deaths over the period, but the data show little impact from the law. One explanation for this lack of effect is the risk compensation hypothesis, which suggests that "safety" improvements are transferred by drivers into increased performance-the amount and speed of travel. Public health policies need to take into account the complex behavioural interactions between travel and safety choices if they are to affect underlying trends.

Evidence that wearing 3-point seat belts saves lives and reduces injuries was reviewed by the Transport and Road Research Laboratory in 1979.' Eight studies comparing the injuries of belted and unbelted vehicle occupants had found reductions in serious injuries of around $60 \%$, and one study of fatal car accidents in Britain had estimated that wearing seat belts would halve the number of deaths. The report noted that seat belt laws existed in 15 countries, but relied primarily on evidence from Australia, where the state of Victoria had introduced legislation in December 1970. The report stated: "The Victoria data suggest that seat belts, when worn, reduced the risk of death by at least 40 per cent." 3

During the parliamentary debate on seat belts in 1979, the Secretary of State for Transport, Mr William Rogers, stated: "Compulsion could save up to 1000 lives and 10000 injuries a year."2 $A$ leading article in the British Medical Journal proposed five courses of government action to reduce road accidents, and, as top priority, claimed that "the case for seat belts is overwhelming and urgent." 3

A law compelling car drivers and their front seat passengers to wear seat belts was finally passed by parliament in July 1981, and introduced from February 1983. For the final House of Commons debate, the Presidents of three Royal Medical Colleges sent a letter to Parliament expressing "despair at the failure of our legislators to take simple steps to reduce this annual carnage."4 Opposition to seat belt legislation, especially within the majority Conservative party, mainly came from MPs concerned that legislation would encroach upon "individual freedom".

However, a study published in 1981 , and mentioned in the Parliamentary debate, had compared the trend in road accident deaths during the 1970s in 13 countries that had brought in seat belt laws with four that had not. ${ }^{56}$ None of the countries except Australia had shown a change in death rates in the years after legislation, and, taken together, the countries without legislation (Britain, Italy, Japan and the United States) had a larger fall in death rates than those introducing seat belt laws. Responding to this report, a statistician at the Department of Transport looked at the effects of seatbelt laws in eight Western Europe countries, and came to much the same conclusions. However, this report, dated April 1981, was not brought to parliament's attention by the Minister during the debate, and its existence only came to light in February $1985 .^{7}$

The government supported two evaluations of the effect of the seat belt law. The first study, funded by the Department of Health, was initiated by a Belfast casualty surgeon. Data were collected from 14 hospital accident departments throughout the United Kingdom (excluding the London area) for 1 year before and 1 year after the introduction of the 
legislation. ${ }^{8}$ Casualty officers recorded details of patients attending hospital accident departments for road traffic accident injuries. There was a $15 \%$ reduction in patients arriving at the 14 hospitals, and proportionately fewer patients with severe injuries (observations on the severity of injuries were made by casualty officers). There were fewer eye injuries and major fractures, but more injuries to abdominal organs. Brain injuries to drivers also increased. A parallel study of deaths, based on coroners' records, was inconclusive. ${ }^{8}$

The second study was contracted by the Department of Transport to two experienced academic mathematicians, who used time-series models of deaths and "killed and serious injuries" (KSI) data to compare the previous 13 years with the 23 months after the law. ${ }^{9}$ There were significantly fewer killed and seriously injured drivers and front seat passengers, but no change for rear seat passengers, cyclists and pedestrians. For deaths alone, the reduction in drivers and front seat passengers was less, while deaths of other road users were substantially greater than expected. The authors estimated that the seat belt law had saved less than 200 lives a year.

In 1986, after 3 years trial, Parliament made the seat belt law permanent. Data are now available to review the public health effect of the law over the 5 years since it introduction.

\section{Methods}

Data on road accident deaths and injuries are collected by three sources: the Office of Population Censuses and Surveys (OPCS); the Department of Transport; and the Department of Health.

OPCS records road accident deaths up to 1 year after an accident. Being based on coroners' verdicts, these data take longer to be notified than police reports at the time of the accident, but, for the same reason, they are more accurate and more complete. The data are published annually in statistics series MB4. Since 1977 OPCS has published a quarterly Monitor (DH4) of deaths from accidents and violence which divides road accidents according to the dead person's mode of travel. Road accidents show monthly variations, rising in the winter months and falling to lower levels in the spring, so an average is best shown by annual figures.

The Department of Transport publishes a report on road accidents annually which also includes tables by road user, as well as numbers of accidents and casualties. Casualties are divided into minor and severe: severity is rated subjectively by individual police shortly after the accident. A "severe" accident can range from a broken finger to a patient admitted to an intensive care ward, but "generally will not include the results of a medical examination."11

A third potential source of data about road accident injuries is the Hospital Inpatient Enquiry (HIPE), published on behalf of the Department of Health by OPCS. However, in contrast to the ICD code used for death certification, HIPE does not code accidents by the external cause of injury, only by the accident diagnosis. It is therefore impossible from this source to make a reliable estimate of hospital deaths and discharges from road accidents alone. Data about home accidents are collected (by the Department of Trade) from a national sample of hospital accident department attendances, but there are no routine data on road accidents collected in casualty departments.

Time series for the period 1976-87 have been constructed for deaths from the DH4 monitors. Similar series were gathered for deaths and injured from the Department of Transport's published data, along with a summary series on population, vehicle licences, accidents and casualties since 1926.

\section{Results}

Figure 1 shows data on road deaths reported by the police from 1976 to 1987, using the Department of Transport's categories of road user. The downward trend from 1976 for pedestrian and "other" road users (ie, motor vehicles) is evident, with a lesser fall in deaths of motor cyclists and little change for pedal cyclists. The "other" category shows a marked fall in the year after introduction of compulsory seat belt wearing, but this can also be seen as variation within the downward trend.

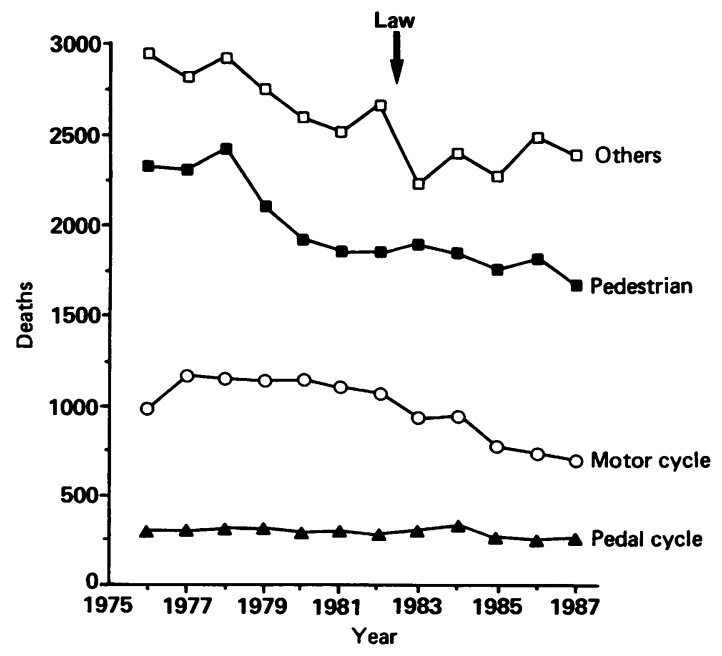

Fig 1 Casualties killed from road accidents, Great Britain 1976-87 
Road accident deaths recorded by OPCS in England and Wales for 1976-87 are shown in fig 2, using a log scale so as to include a trend for all deaths. Data for 1981 are missing because of the strike by local registrars of deaths. In 1983 there was a modest fall in deaths of motor vehicle drivers and motor cyclists, and to a lesser extent motor vehicle passengers, but this was partially offset by a rise in deaths of pedestrians and pedal cyclists. From 1985 motor vehicle drivers and passenger deaths were rising again. The net effect on all road deaths was a slow downward trend.

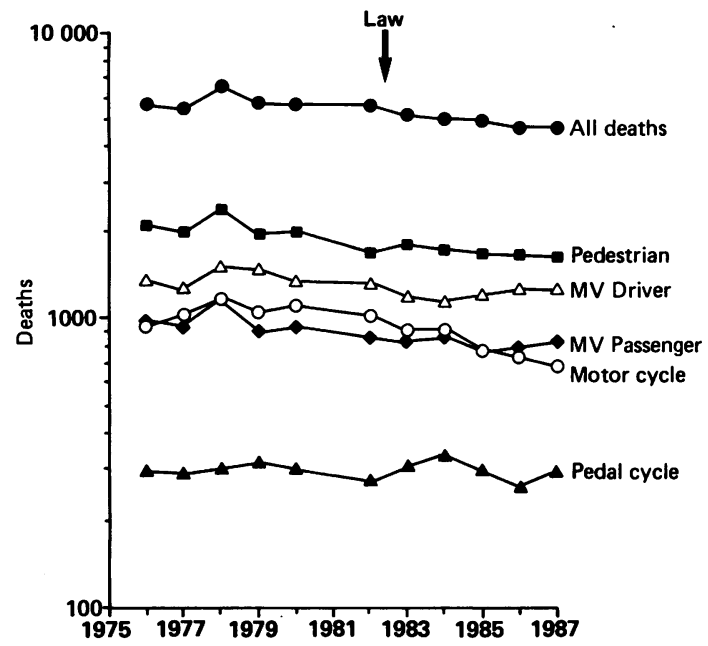

Fig 2 Road accident deaths, England \& Wales 1976-87

Figure 3 shows police data at 5 year intervals for Great Britain from 1926, when statistics by road user were first recorded. The population has risen slowly from 44 million in 1926 to 55 million in 1986. Vehicle licences (as a proxy for exposure) rose steeply, but with a flattening curve since the mid sixties. Casualties and accidents rose before, and again after, the war (data for the war years are not available). They reached a peak in the 1960s, and have slowly fallen since then.

The number of people killed on the roads in 1927 (total 5125) is remarkably close to the number killed in 1987 (total 5329). The proportions have altered by road user: there are many more deaths of people within motor vehicles (described in the table as "others"), and falls in pedestrians, pedal cyclists and motor cyclists. Data on exposure are not reported.

\section{Discussion}

Avery, ${ }^{11}$ in a British Medical Journal leading article 1 year after compulsory car front seat belts were introduced, claimed the law as "a remarkable success story in road safety legislation . . . a saving of 350 lives

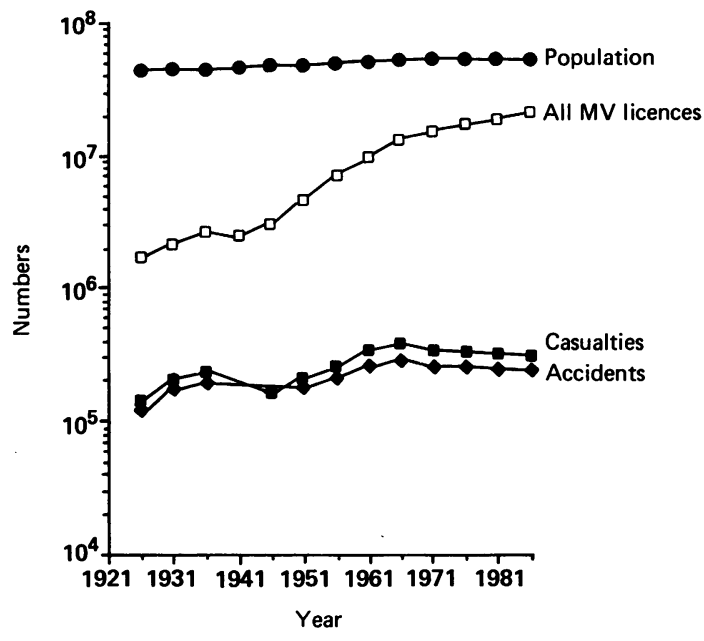

Fig 3 Population, road licences, accidents and casualties, 5-yearly, Great Britain 1926-86

and 4500 serious injuries". He recommended new legislation for compulsory wearing of rear seat belts. When the Casualty Surgeons' study ${ }^{8}$ was published, Mackay, in the same Journal, claimed that the law was saving about 400 lives a year, and was "one the most successful pieces of public health legislation ever". ${ }^{12}$ Yet the evidence from routine data is not as compelling as these commentaries suggest.

Table Road vehicles, accidents and casualties, Great Britain 1927 and 1987.

\begin{tabular}{lrr}
\hline & 1927 & 1987 \\
\hline Population (millions) & $44 \cdot 0$ & $55 \cdot 4$ \\
Road Vehicles (millions) & 1.9 & $22 \cdot 2$ \\
Accidents (thousands) & 134 & 239 \\
Killed & & \\
$\quad$ Pedestrians & 2774 & 1703 \\
Pedal cyclists & 644 & 280 \\
Motor cyclists & 1175 & 723 \\
Others & 736 & 2419 \\
All killed and injured (thousands) & 154 & 311 \\
\hline
\end{tabular}

Source: Department of Transport. Road Accidents Great Britain 1987. London: HMSO, 1988 (table 2).

What are the limitations to the two published official evaluative studies? The Casualty Surgeons' study $^{8}$ used data for 1 year before and 1 year after the seat belt law was introduced. Moreover, it only looked at car drivers and their passengers: it excluded other vehicle drivers, motor cyclists, pedal cyclists and 
pedestrians. Thus it could not estimate whether the legislation had been offset by any increase in road accident injuries for non-car-users. The interrupted time series model of Harvey and Durbin ${ }^{9}$ used a longer period before the law (13 years), weighted for proximity. But the post-law period, less than 2 years, was short, given the seasonal periodicity of the data. An effect of the law was found with the killed and seriously injured (KSI) data, but the results for deaths alone were equivocal.

A Transport and Road Research Laboratory study has looked at the reliability of non-fatal injury data recorded by the police. The severity of 3641 patients attending a single hospital accident department during 1 year were compared using the Ministry of Transport (MOT) injury classification and the Abbreviated Injury Scale (AIS). ${ }^{13}$ The MOT "serious" injuries ranged on the AIS from minor (scale point 1) to critical (scale point 5). Moreover, nearly $30 \%$ of the casualty attenders were found not to have been reported to the police, with the highest non-reporting rate in seriously injured cyclists. Police data may be too unreliable for epidemiological conclusions.

Few epidemiological studies show a simple causeeffect relationship between mortality trends and a single environmental change, especially in preventive interventions. G S Wilde, an American psychologist, has suggested that "risk homeostasis" may explain the lack of impact of the seat belt law. ${ }^{14} 15$ Wilde argues that complex social systems adjust to changed levels of risk in accident and other public health settings. Adams proposes a more testable version of this hypothesis, "risk compensation". 6 Harvey and Durbin ${ }^{9}$ recognised the possibility of risk compensation in their analysis: "The figures for KSI casualties lead one to reject the risk compensation hypothesis. On the other hand, the killed figures do lend support to the hypothesis".

Risk compensation suggests that when drivers feel safer, they may take on a new level of driving behaviour (eg, driving more aggressively), adjusting to their individual level of risk. They may also increase their risk exposure by driving further. Because serious accidents are so rare to any individual, this population change is imperceptible, but changing behaviour is clearly seen over time, for example, with improvements in car road holding and performance. Risk compensation is an important alternative to simple mechanistic models of road safety. As Adams suggests, the public health objective of greater safety is cancelled out by the transport objective of more travel-more cars, more journeys and greater speed. The potential benefits of road "safety" improvements are consumed as performance benefits.

Risk compensation can also be accompanied by redistribution of risks. This may be evident in the road death statistics: in Great Britain in the year after the law, there was a fall in deaths for car drivers and front seat passengers, but a rise in deaths for rear passengers, cyclists and pedestrians. In subsequent years these small changes have evened out and the longer term trend for all road deaths continued. Redistribution of risks also means that "safety" must include an estimate of exposure. As Adams has commented, we have fewer child road deaths now not because the roads are "safer" but because fewer children play in the roads. ${ }^{6}$ Equally, the long term trend of falling pedestrian or cyclist deaths may reflect the fact that, year by year, these two groups of users have been increasingly forced off the roads.

Whether risk compensation is an adequate explanation of driving behaviour and road safety remains open to debate. Many people resist the idea, since it dampens enthusiasm for simple, "obvious" policy interventions; but they must recognise the possibility that mechanical "safety improvements" (protection within cars, limitation of pedestrian access) are being translated into improved performance (higher average speeds, faster cornering). Research needs to address the causes of the larger underlying trend of falling deaths and serious injuries in Britain since the 1960s. We cannot expect either car manufacturers, or their customers, the drivers, to welcome "safety" measures that seriously impede individual transport performance. Public health legislation will have to consider the balance between public risk and individual benefits in transport as in other areas.

Address for correspondence and reprints: Mark McCarthy, FFCM, MRCP, Department of Community Medicine, University College London, 66-72 Gower St, London WC1E 6EA.

\section{References}

${ }^{1}$ Anonymous. The protection afforded by seat belts. Crowthorne: Transport and Road Research Laboratory, 1979 (supplementary report 449).

${ }^{2}$ Rodgers W. Hansard 22 March 1979, col 1720.

3 Anonymous. Priorities in road accidents. Br Med J 1979; i: 287-8.

${ }^{4}$ Leichner $\mathbf{H}$. Lives, liberty and seat belts in Britain: lessons for the United States. Int J Health Serv 1986; 16: 213-26.

5 Adams JGU. The efficacy of seatbelt legislation: a comparative study of road accident fatality statistics from 18 countries. London: Department of Geography, University College London, 1981.

${ }^{6}$ Adams JGU. Risk and freedom. Cardiff: Transport Publishing Projects, 1985.

${ }^{7}$ Hamer M. Report questions whether seat belts save lives. New Scientist 1985, 7 February (no 1442): 7.

${ }^{8}$ Rutherford WH, Greenfield T, Hayes HRM, Nelson JK. The medical effects of seatbelt legislation in the United Kingdom. London: HMSO 1985 (DHSS Office of the Chief Scientist Research Report 13). 
${ }^{9}$ Harvey AC, Durbin J. The effects of seat belt legislation on British road casualties: a case study in structural time series modelling. J R Statist Soc A 1986; 149: 187-227.

${ }^{10}$ Department of Transport. Road accidents Great Britain 1987. London: HMSO, 1988.

${ }^{11}$ Avery JG. Seat belt success: where next? Br Med J 1984; 288: 662-3.

${ }^{12}$ Mackay M. Seat belts and risk compensation. $\mathrm{Br}$ Med $\mathrm{J}$ 1985; 291: 757-8.
${ }^{13}$ Hobbs CA, Grattan E, Hobbs JA. Classification of injury severity by length of stay in hospital. Crowthorne: Transport and Road Research Laboratory, 1979 (TRRL Laboratory Report 871).

14 Wilde GJS. The theory of risk homeostasis: implications for safety and health. Risk Analysis 1982; 2: 209-25.

${ }^{15}$ Wilde GJS. Risk homeostasis theory and traffic accidents: propositions, deductions and discussion of dissension in recent reactions. Ergonomics 1988; 31: 441-68. 